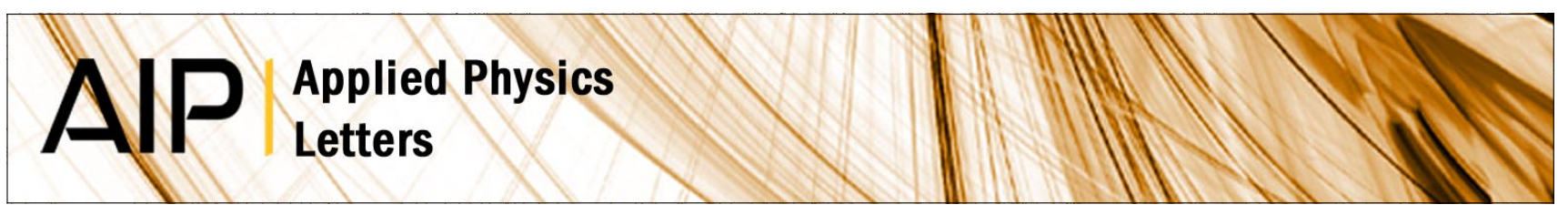

\title{
Efficiency droop in InSb/AllnSb quantum-well light-emitting diodes
}

G. R. Nash and B. I. Mirza

Citation: Appl. Phys. Lett. 102, 011127 (2013); doi: 10.1063/1.4773182

View online: http://dx.doi.org/10.1063/1.4773182

View Table of Contents: http://apl.aip.org/resource/1/APPLAB/v102/i1

Published by the American Institute of Physics.

\section{Related Articles}

Emission characteristics in solution-processed asymmetric white alternating current field-induced polymer electroluminescent devices

APL: Org. Electron. Photonics 6, 7 (2013)

Effect of multiquantum barriers in performance enhancement of GaN-based light-emitting diodes Appl. Phys. Lett. 102, 013507 (2013)

Emission characteristics in solution-processed asymmetric white alternating current field-induced polymer electroluminescent devices

Appl. Phys. Lett. 102, 013307 (2013)

Influence of dislocation density on carrier injection in InGaN/GaN light-emitting diodes operated with alternating current

Appl. Phys. Lett. 102, 011115 (2013)

Efficient tandem organic light-emitting device based on photovoltaic-type connector with positive cycle APL: Org. Electron. Photonics 6, 4 (2013)

\section{Additional information on Appl. Phys. Lett.}

Journal Homepage: http://apl.aip.org/

Journal Information: http://apl.aip.org/about/about_the_journal

Top downloads: http://apl.aip.org/features/most_downloaded

Information for Authors: http://apl.aip.org/authors

\section{ADVERTISEMENT}

\section{AIP Applied Physics Letters}

\section{EXPLORE WHAT'S NEW IN APL}

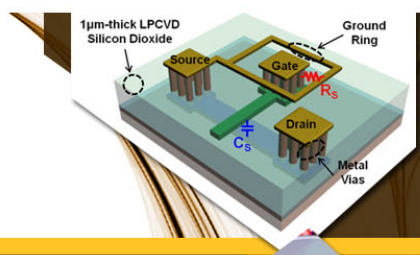

SURFACES AND INTERFACES

Focusing on physical, chemical, biological, structural, optical, magnetic and electrical properties of surfaces and interfaces, and more.. 


\title{
Efficiency droop in InSb/AllnSb quantum-well light-emitting diodes
}

\author{
G. R. Nash ${ }^{1, a)}$ and B. I. Mirza ${ }^{2}$ \\ ${ }^{1}$ College of Engineering, Mathematics and Physical Sciences, University of Exeter, Exeter EX4 4QF, \\ United Kingdom \\ ${ }^{2}$ Photonics Group, Department of Electrical and Electronic Engineering, University of Bristol, \\ Bristol BS8 IUB, United Kingdom
}

(Received 14 September 2012; accepted 10 December 2012; published online 10 January 2013)

Efficiency droop in $\mathrm{InSb} / \mathrm{Al}_{\mathrm{x}} \mathrm{In}_{1-\mathrm{x}} \mathrm{Sb}$ quantum-well light-emitting diodes has been investigated as a function of temperature for devices containing $20 \mathrm{~nm}, 40 \mathrm{~nm}$, and $100 \mathrm{~nm}$ wide quantum well active regions. The amount of droop is greatest at low temperatures in device with the widest wells. (c) 2013 American Institute of Physics. [http://dx.doi.org/10.1063/1.4773182]

Efficiency droop in nitride-based light-emitting diodes, where the efficiency of the devices decreases significantly at high currents, has been the subject of much investigation over the last few years, with a continuing debate as to the origin of this phenomenon. As a result of efficiency droop in InGaN/GaN quantum well light-emitting-diodes (QWLEDs), the maximum optical power output is achieved at low pump currents, typically a few mA. ${ }^{1}$ This has limited the use of these LEDs in high current, high output power applications. Various mechanisms have been suggested as the physical origin of the efficiency droop including: carrier overflow from the QW at high forward currents, ${ }^{1-3}$ Auger and indirect Auger recombination, ${ }^{4,5}$ junction heating ${ }^{6}$ which would reduce the radiative recombination efficiency, recombination and escape of carriers via defects, ${ }^{7-9}$ and carrier localisation. ${ }^{10,11}$ However, very little attention has been given to efficiency droop in LEDs made from different materials. In this paper, we investigate efficiency droop in a very different material system; the narrow bandgap InSb/AlInSb system. This system is attractive for realizing mid-infrared optoelectronic components, ${ }^{12-14}$ both for use in applications such as components for non-dispersive infrared gas sensing, ${ }^{15}$ but also as a way of exploiting the quantum effects arising from the very small electron mass. ${ }^{16,17}$ Although the factors limiting the efficiency of narrow bandgap LEDs have been studied extensively over the last couple of decades, ${ }^{18}$ there have been very few reports and analysis of efficiency droop. For example, Krier ${ }^{19}$ and Das and Tobin ${ }^{20}$ observed efficiency droop in InAs heterostructure and interband cascade Type IIsuperlattice based LEDs, respectively, but only when the devices were driven with long pulses, suggesting that heating was the origin of the droop. In this work, we show that efficiency droop in InSb/AlInSb QWLEDs is greatest at low temperature in devices with the widest quantum wells. This may be related to the escape of carriers from the wells, caused by carrier-carrier scattering, allowing them to recombine non-radiatively in the barriers.

The samples studied were grown by molecular-beam epitaxy on SI GaAs substrates. A schematic diagram of the QW LED structure is shown in Fig. 1. The InSb QWs were grown on top of a 3- $\mu$ m-thick $\mathrm{Al}_{x} \mathrm{In}_{1-x} \mathrm{Sb}$ barrier and were

\footnotetext{
${ }^{\text {a) }}$ Author to whom correspondence should be addressed. Electronic mail: g.r.nash@exeter.ac.uk.
}

capped with a 120-nm-thick layer of $\mathrm{Al}_{x} \mathrm{In}_{1-x} \mathrm{Sb}$. Tellurium and beryllium were used to dope the layers $n$ type and $p$ type to nominal levels of $2 \times 10^{17}$ and $5 \times 10^{18} \mathrm{~cm}^{-3}$, respectively. Three QW LED structures were investigated: QW1 had a $20 \mathrm{~nm}$ undoped InSb quantum well with a barrier composition of $x=0.143$; QW2 had a $40 \mathrm{~nm}$ undoped InSb well with a barrier composition of $x=0.077$; and QW3 had a $100 \mathrm{~nm}$ undoped InSb well with a barrier composition of $x=0.025$. The composition of the barrier layers was determined by x-ray diffraction measurements. Devices consisted of 16 elements connected in series yielding a total emitting area of $1 \mathrm{~mm}^{2}$. More details concerning device structure, growth, and doping can be found in Ref. 12 and references therein. The bandstructure of the devices (calculated using an eight-band $\mathbf{k} \cdot \mathbf{p}$ model) can be found in Ref. 17 . The very small electron effective mass $\left(\sim 0.014 \mathrm{~m}_{\mathrm{o}}\right)$ in InSb, approximately one fifth that in GaAs, leads to strong quantum confinement even in relatively wide quantum wells. For example, the separation between the first and second electron subbands in the $100 \mathrm{~nm}$ wide wells described here is approximately $8 \mathrm{meV}$ at $15 \mathrm{~K}$ (under zero net bias), much greater than kT. Even in these wide wells, the effective confinement energy (the difference between the lowest electron subband and the barrier conduction band) also has a value $(\sim 20 \mathrm{meV}$ at $15 \mathrm{~K}$ ) much greater than $\mathrm{kT}$. At low temperatures, the properties of all the LEDs are, therefore, dominated by the quantization in the quantum wells.

Measurements of the emittance as a function of current were performed with the QWLEDs glued onto standard ceramic headers and mounted on the cold finger of a closedcycle cryostat. Devices were driven under forward bias with a $1 \mathrm{kHz}$ square waveform (50\% duty cycle), at peak injection currents ranging from 0.5 to $20 \mathrm{~mA}$. No evidence of device heating was found as a result of using a $50 \%$ duty cycle drive waveform. Emitted light from the diodes exited the cryostat through a $2 \mathrm{~mm}$ thick $\mathrm{CaF}_{2}$ window, and was collimated using a $f / 1.0 \mathrm{CaF}_{2}$ lens. The light was then directed by a $\mathrm{MgF}_{2}$ mirror on a flip mount either through a grating spectrometer with a $5 \mu \mathrm{m}$ blazed grating, or directly to a calibrated detector (either an InSb photovoltaic detector or a $\mathrm{HgCdTe}$ photoconductive detector was used), cooled to $77 \mathrm{~K}$. The signal from the detector was then amplified by a low noise preamplifier, and passed to a lock-in amplifier for phase sensitive measurement. The collection efficiency of 


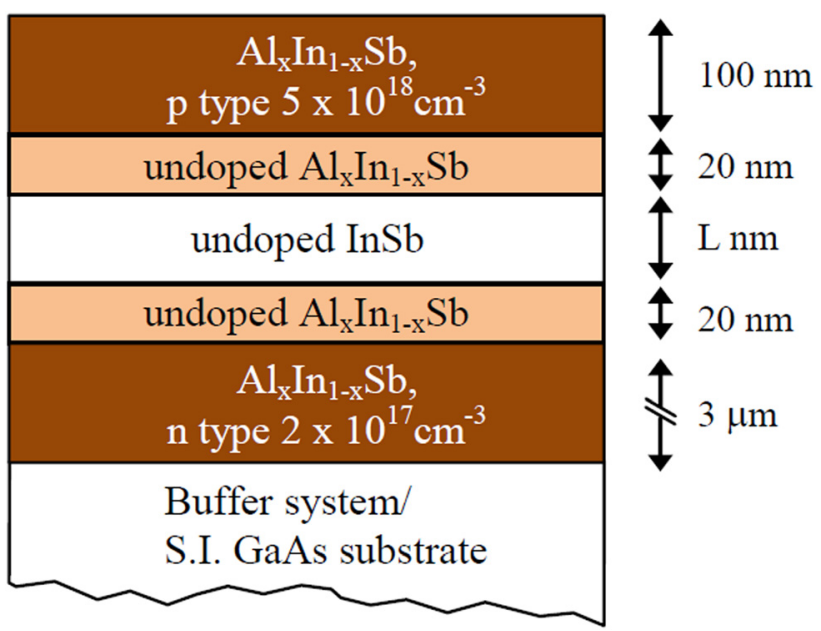

FIG. 1. Schematic cross-section showing the structure of the QW LEDs. L is the quantum well thickness.

the optics was estimated, assuming that the diode was emitting isotropically, to be approximately $6 \%$. In addition, lens transmission was taken to be $96 \%$ with the only losses being a $2 \%$ reflection off each face. Values for $\eta_{\text {ext }}$ were estimated by integrating the calibrated emission spectrum and dividing by $J / q$, where $J$ is the current density and $q$ is the charge on the electron. From this result, $\eta_{\text {int }}$ was calculated by correcting for the large difference in refractive index at the deviceair interface. This is achieved by multiplying $\eta_{\text {ext }}$ by $n(n+1)^{2}$, where $\mathrm{n}$ is the refractive index of the active layer. $^{21}$

In Figure 2, the measured emittance is plotted as a function of current, from $25 \mathrm{~K}$ to room temperature, for the three quantum well LEDs. The emittance from QW1 at $300 \mathrm{~K}$ shows an approximately linear dependence on current over the full current range. As the temperature is decreased, the emittance continues to increase with increasing current although it follows an approximately super-linear dependence below $100 \mathrm{~K}$. For QW1, the maximum emittance $\left(\mathrm{L}_{\max }\right)$ is greatest at $25 \mathrm{~K}$ (the lowest temperature measured) and $5 \mathrm{~mA}$ (the highest current measured). Device QW2 again shows an approximately linear dependence on current at high temperature $(295 \mathrm{~K})$ although this quickly turns sublinear as the temperature is decreased to $195 \mathrm{~K}$. On further decreasing the temperature to $95 \mathrm{~K}, \mathrm{~L}_{\max }$ is no longer at the highest injection current, which for this measurement is $50 \mathrm{~mA}$, and instead occurs at approximately $40 \mathrm{~mA}$. At $45 \mathrm{~K}$, $\mathrm{L}_{\text {max }}$ occurs at $35 \mathrm{~mA}$ and at $25 \mathrm{~K}$ this reduces to $30 \mathrm{~mA}$ where it is approximately $10 \%$ greater than the emittance at $50 \mathrm{~mA}$. The trend of $\mathrm{L}_{\max }$ occurring at currents lower than the maximum applied current becomes even more pronounced in QW3. The emittance in this device is sub-linear at all temperatures and $\mathrm{L}_{\max }$ is at $25 \mathrm{~mA}, 15 \mathrm{~mA}$, and $10 \mathrm{~mA}$ at $95 \mathrm{~K}, 45 \mathrm{~K}$, and $25 \mathrm{~K}$, respectively. At $25 \mathrm{~K}, \mathrm{~L}_{\max }$ is approximately three times greater than the emittance at $50 \mathrm{~mA}$ at this temperature. The decreasing strength of the droop with increasing temperature is not consistent with non-radiative Auger recombination being its dominant cause.

In Figure 3, the internal quantum efficiency (IQE) is plotted as a function of current, at $15 \mathrm{~K}$, for both QW2 and
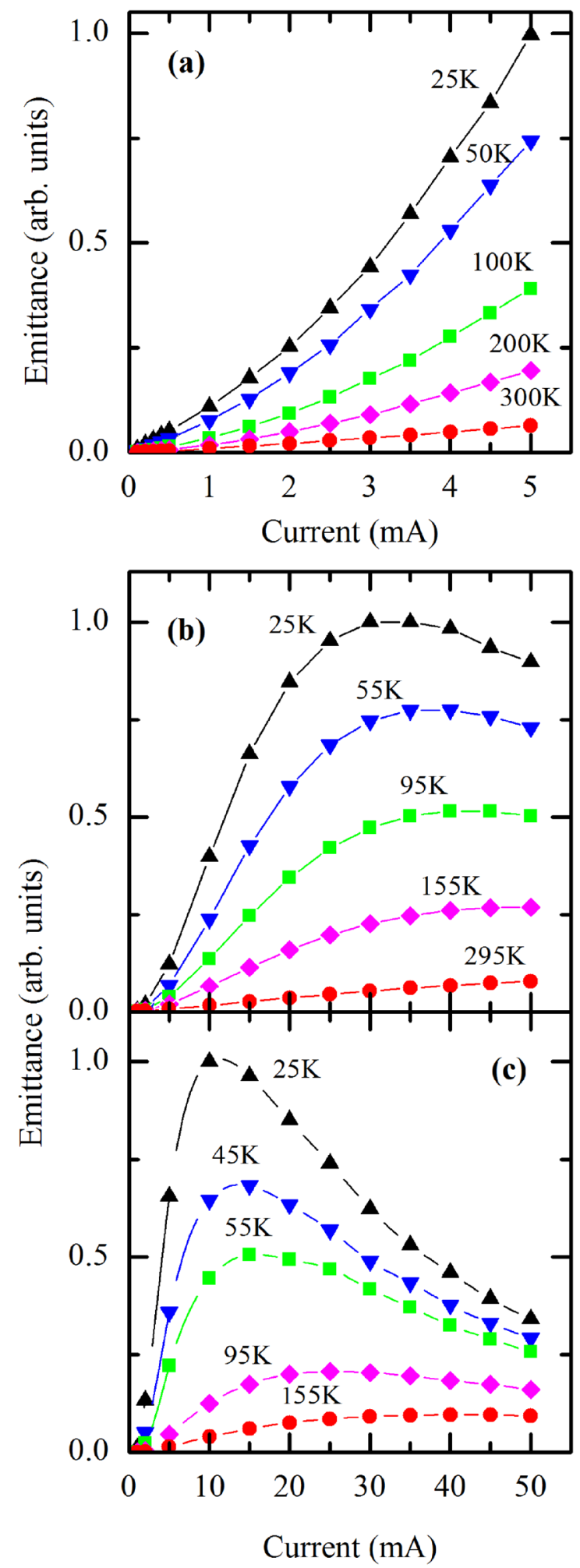

FIG. 2. Measured light-current characteristics as a function of temperature for LEDs containing (a) $20 \mathrm{~nm}$ wide well (QW1), (b) $40 \mathrm{~nm}$ wide well (QW2), and (c) $100 \mathrm{~nm}$ QW3. The lines are a guide to the eye only.

QW3, showing the reduction in internal quantum efficiency at high currents. This efficiency droop was not observed in either bulk InSb, or $\mathrm{Al}_{\mathrm{x}} \mathrm{In}_{1-\mathrm{x}} \mathrm{Sb} \mathrm{LEDs},{ }^{18}$ with compositions similar to those of the barriers in QW2 and QW2 studied here $(x=0.25$ and $x=0.875)$, under the same drive currents. The absence of the droop in the InSb LEDs, where the bandgap $(\sim 240 \mathrm{meV}$ at $15 \mathrm{~K})$ is comparable to the effective 


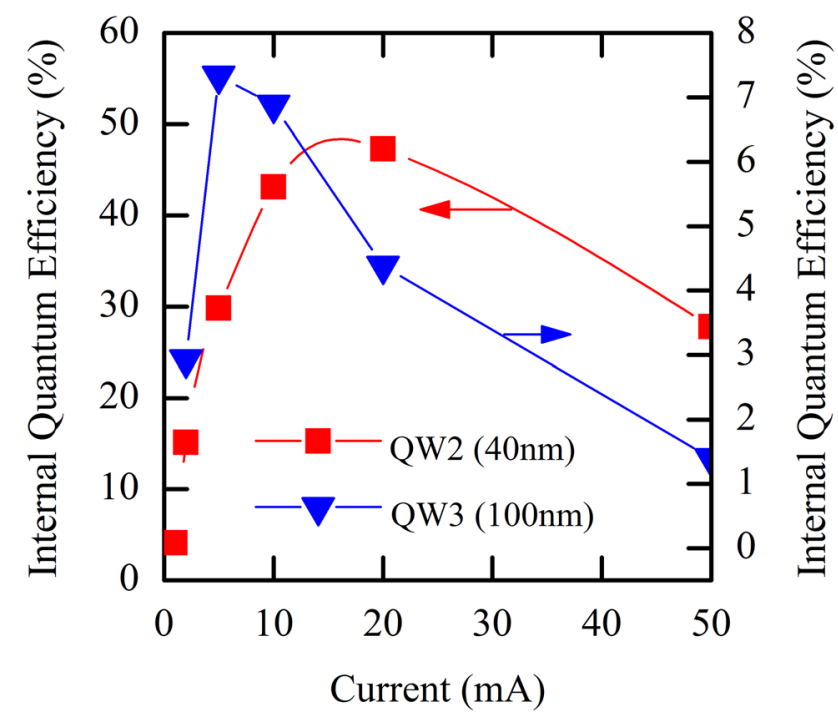

FIG. 3. Measured internal quantum efficiency plotted as a function current at $15 \mathrm{~K}$ for QW2 (40 nm wide well) and QW3 (100 nm wide well). The lines are a guide to the eye only.

bandgap (energy difference between the first electron and hole subbands) in the sample with the widest quantum well, where the efficiency droop was largest, again suggests that Auger recombination is not the dominant cause of the droop. In addition, as mentioned above, even in the sample containing the widest quantum well, the effective confinement energy is much greater than $\mathrm{kT}$ over the temperature range in which efficiency droop is exhibited. This suggests that a simple thermal escape process, which would lead to an increase in the droop with increasing temperature, is also not the dominant mechanism. One possible explanation for the observed efficiency droop in these QW devices is a variant of the density-activated defect-recombination (DADR) proposed by Hader et al., ${ }^{9}$ where in our case carrier-carrier scattering at high current densities would enable carriers to escape from the quantum well. This would allow nonradiative recombination in either the undoped, or highly doped $\mathrm{p}$ and $\mathrm{n}, \mathrm{Al}_{\mathrm{x}} \mathrm{In}_{1-\mathrm{x}} \mathrm{Sb}$ barriers. At low temperatures, Shockley-Read-Hall (SRH) recombination is thought to dominate recombination in bulk $\mathrm{Al}_{\mathrm{x}} \mathrm{In}_{1-\mathrm{x}} \mathrm{Sb}$ LEDs,${ }^{18}$ possibly related to defects associated with the aluminium. ${ }^{14}$ At $25 \mathrm{~K}$, and at $20 \mathrm{~mA}$, the measured IQE measured was $8.4 \%$ and $0.2 \%$ for bulk LEDs with $\mathrm{Al}_{0.025} \mathrm{In}_{0.975} \mathrm{Sb}$ and $\mathrm{Al}_{0.0875} \mathrm{In}_{0.9125} \mathrm{Sb}$ active regions, respectively. In these bulk devices, the doping level in the active region devices (approximately $1 \times 10^{6} \mathrm{~cm}^{-3}$ ) had been optimized to minimize SRH recombination, and it is, therefore, likely that SRH recombination will be greater in the barriers of the QWLEDs described here.

We have previously obtained estimated values of the effective carrier temperature in the QWLEDs, at low temperature and under net bias, of $105 \mathrm{~K}$ and $129 \mathrm{~K}$ for QW2 and QW3, respectively, ${ }^{17}$ corresponding to carrier energies of approximately $10 \mathrm{meV}$. In comparison, the energy difference between the lowest electron subband and the barrier conduction band is approximately $20 \mathrm{meV}$ and $45 \mathrm{meV}$ for QW2 and QW3, respectively (at low temperature under net bias). Carrier-carrier scattering could, therefore, lead to carriers escaping from the quantum wells (particularly at low temperatures where transitions involving higher subbands contribute to the overall emission spectrum ${ }^{17}$ ). In addition, the observed temperature dependence of the droop, with the current at which maximum emission occurs increasing with increasing temperature, is consistent with the recent analysis of the temperature dependence of droop in GaN-based diodes using the DADR model. ${ }^{22}$

Evidence for recombination in the $\mathrm{Al}_{\mathrm{x}} \mathrm{In}_{1-\mathrm{x}} \mathrm{Sb}$ barriers can be seen in the emission spectrum of QW3, which is shown in Figure 4. As the current is increased, a clear shoulder emerges in the emission spectrum at an energy of approximately $280 \mathrm{meV}$, which is close to the predicted bandgap $(290 \mathrm{eV})$ of $\mathrm{Al}_{0.025} \mathrm{In}_{0.975} \mathrm{Sb}^{23}$ Note that the minimum in the measured spectra at around $292 \mathrm{meV}$ is due to $\mathrm{CO}_{2}$ absorption, and the inset of Figure 4 shows the emission spectrum of QW3, at $20 \mathrm{~mA}$, corrected for the $\mathrm{CO}_{2}$ absorption (the transmission through the $\mathrm{CO}_{2}$ was calculated assuming a $\mathrm{CO}_{2}$ concentration of $450 \mathrm{ppm}$, an effective optical path length of $3.23 \mathrm{~m}$, and spectrometer resolution of $50 \mathrm{~nm}$ (see Ref. 24). This confirms that this peak is not an artefact of the $\mathrm{CO}_{2}$ absorption. No clear feature corresponding to recombination in the barrier was observed in the measured emission spectrum for QW2, but this is probably due to the very small radiative component of recombination in this composition of $\mathrm{Al}_{\mathrm{x}} \mathrm{In}_{1-\mathrm{x}} \mathrm{Sb}$ (the IQE for the bulk device with equivalent composition was $0.02 \%$ at $15 \mathrm{~K}$ ).

Measurements of the light-current characteristics of $\mathrm{InSb} / \mathrm{AlInSb}$ QWLEDs have been performed as a function of temperature for devices containing $20 \mathrm{~nm}, 40 \mathrm{~nm}$, and $100 \mathrm{~nm}$ wide quantum wells. At low temperatures, the devices containing the widest wells exhibit "efficiency droop," where the internal quantum efficiency reduces at high current. One possible explanation for this observed behavior is a variant of DADR, where carrier-carrier scattering allows

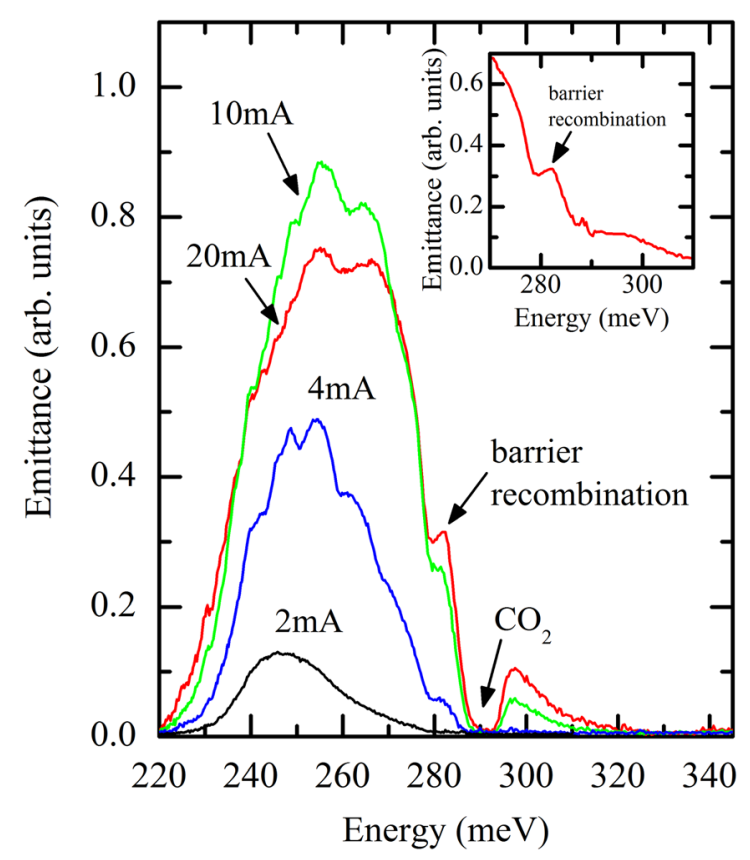

FIG. 4. Measured emission spectrum for QW3 as a function of current at $15 \mathrm{~K}$. The inset shows the measured spectrum at $20 \mathrm{~mA}$ corrected for $\mathrm{CO}_{2}$ absorption. 
carriers to escape the quantum well and to recombine nonradiatively in the barriers. Further work is required to conclusively identify the mechanism of the efficiency droop.

${ }^{1}$ M. H. Kim, M. F. Schubert, Q. Dai, J. K. Kim, E. F. Schubert, J. Piprek, and Y. Park, Appl. Phys. Lett. 91, 183507 (2007).

${ }^{2}$ Y.-L. Li, Y.-R. Huang, and Y.-H. Lai, Appl. Phys. Lett. 91, 181113 (2007).

${ }^{3}$ I. V. Rozhansky and D. A. Zakheim, Phys. Status Solidi A 204, 227 (2007).

${ }^{4}$ Y. C. Shen, G. O. Mueller, S. Watanabe, N. F. Gardner, A. Munkholm, and M. R. Krames. Appl. Phys. Lett. 91, 141101 (2007).

${ }^{5}$ E. Kiopakis, P. Rinke, K. T. Delaney, and C. G. Van de Walle, Appl. Phys. Lett. 98, 161107 (2011).

${ }^{6}$ A. A. Efremov, N. I. Bochkareva, R. I. Gorbunov, D. A. Lavrinovich, Yu. T. Rebane, D. V. Tarkhin, and Yu. G. Shreter, Semiconductors 40(5), 605-610 (2006).

${ }^{7}$ B. Monemar and B. E. Sernelius, Appl. Phys. Lett. 91, 181103 (2007).

${ }^{8}$ M. F. Schubert, S. Chhajed, J. K. Kim, E. F. Schubert, D. D. Koleske, M. H. Crawford, S. R. Lee, A. J. Fischer, G. Thaler, and M. A. Banas, Appl. Phys. Lett. 91, 231114 (2007).

${ }^{9}$ J. Hader, J. V. Moloney, and S. W. Koch, Appl. Phys. Lett. 96, 221106 (2010).

${ }^{10}$ S. Hammersley, D. Watson-Parris, P. Dawson, M. J. Godfrey, T. J. Badcock, M. J. Kappers, C. McAleese, R. A. Oliver, and C. J. Humphreys, J. Appl. Phys. 111, 083512 (2012).

${ }^{11}$ H. Y. Ryu, D. S. Shin, and J. I. Shim, Appl. Phys. Lett. 100, 131109 (2012).
${ }^{12}$ G. R. Nash, M. K. Haigh, H. R. Hardaway, L. Buckle, A. D. Andreev, N. T. Gordon, S. J. Smith, M. T. Emeny, and T. Ashley, Appl. Phys. Lett. 88, 051107 (2006).

${ }^{13}$ B. I. Mirza, G. R. Nash, S. J. Smith, M. K. Haigh, L. Buckle, M. T. Emeny, and T. Ashley, Appl. Phys. Lett. 89, 131110 (2006).

${ }^{14}$ M. K. Haigh, G. R. Nash, S. J. Smith, L. Buckle, M. T. Emeny, and T. Ashley, Appl. Phys. Lett. 90, 231116 (2007).

${ }^{15}$ G. R. Nash, H. L. Forman, S. J. Smith, P. B. Robinson, L. Buckle, S. D. Coomber, M. T. Emeny, N. T. Gordon, and T. Ashley, IEEE Sens. J. 9, 1240 (2009).

${ }^{16}$ J. Li, A. M. Gilbertson, K. L. Litvinenko, L. F. Cohen, and S. K. Clowes, Phys. Rev. B 85, 045431 (2012).

${ }^{17}$ T. G. Tenev, B. I. Mirza, G. R. Nash, M. Fearn, S. J. Smith, L. Buckle, M. T. Emeny, T. Ashley, J. H. Jefferson, and C. J. Lambert, Phys. Rev. B 79, 085301 (2009).

${ }^{18}$ B. I. Mirza, G. R. Nash, S. J. Smith, L. Buckle, S. D. Coomber, M. T. Emeny, and T. Ashley, J. Appl. Phys. 104, 063113 (2008).

${ }^{19}$ A. Krier, Phil. Trans. R. Soc. A 359, 599 (2001).

${ }^{20}$ N. C. Das and M. S. Tobin, Solid-State Electron. 50, 1612 (2006).

${ }^{21}$ T. S. Moss, G. J. Burrell, and B. Ellis, Semiconductor Opto-Electronics, 1st ed. (Butterworths, London, 1973), p. 244.

${ }^{22}$ J. Hader, J. V. Moloney, and S. W. Koch, Appl. Phys. Lett. 99, 181127 (2011).

${ }^{23}$ N. Dai, F. Brown, R. E. Doezema, S. J. Chung, K. J. Goldammer, and M. B. Santos, Appl. Phys. Lett. 73, 3132 (1998).

${ }^{24}$ The EPA $\mathrm{CO}_{2}$ database used to calculate the $\mathrm{CO}_{2}$ absorption in this experiment can be found at http://www.epa.gov/ttn/emc/ftir/welcome.html. 